\title{
Distribution of Pseudosclerotia of Monilinia vaccinii-corymbosi and Risk of Apothecial Emergence Following Mechanical Cultivation
}

\author{
H. K. Ngugi, H. Scherm, and D. S. NeSmith
}

First and second authors: Department of Plant Pathology, University of Georgia, Athens 30602; and third author: Department of Horticulture, Georgia Station, University of Georgia, Griffin 30223. Accepted for publication 3 April 2002.

\begin{abstract}
Ngugi, H. K., Scherm, H., and NeSmith, D. S. 2002. Distribution of pseudosclerotia of Monilinia vaccinii-corymbosi and risk of apothecial emergence following mechanical cultivation. Phytopathology 92:877-883.

Pseudosclerotia (infected, mummified fruit) of Monilinia vacciniicorymbosi overwinter on the orchard floor and germinate to produce apothecia in early spring, providing the only source of primary inoculum for mummy berry disease of blueberry. Three experiments were carried out to develop a model for the relative efficacy of mechanical cultivation in reducing the risk associated with primary inoculum. In the first experiment, apothecial emergence from pseudosclerotia buried $0,1.5,3$, 6 , and $10 \mathrm{~cm}$ below the soil surface was monitored to determine the critical depth necessary to inhibit emergence. No apothecia emerged from pseudosclerotia buried at depths of $\geq 3 \mathrm{~cm}$, and the critical depth of burial was determined at $2.6 \mathrm{~cm}$ by regression analysis. In the second experiment, pseudosclerotia or plastic beads (used as surrogates for pseudosclerotia) were placed on the soil surface of experimental plots before cultivation with an in-row rotary cultivator, a disc harrow, or a rotary cultivator with each implement operated in a single pass. Vertical distribution profiles of pseudosclerotia or beads in the topsoil were

was $20.9,52.6$, and $78.6 \%$ for the in-row rotary cultivator, the disc harrow, and the rotary cultivator, respectively. For all three implements, vertical distribution profiles of pseudosclerotia and plastic beads were very similar, allowing the latter to be used in subsequent experiments in commercial fields. In the third experiment, two blueberry plantings were surveyed to determine the horizontal distribution of pseudosclerotia on the orchard floor with distance from the crowns of the plants. The greatest frequency of pseudosclerotia occurred between 30 and $40 \mathrm{~cm}$ from the plants. Based on measurements of the distance from plants within which different implements can operate, the proportion of pseudosclerotia accessible by cultivation ranged from $58.7 \%$ for the disc harrow to $87.2 \%$ for the in-row rotary cultivator. Taken together, results from the three experiments indicated that cultivation with a single implement can reduce risk of apothecial emergence by about $50 \%$. More effective risk reductions may be obtained by combining implements that result in deep burial of pseudosclerotia with those that have access to pseudosclerotia near the plants. This was demonstrated by a commercial cultivation method that utilized three passes of different implements and resulted in extensive reshaping of plant beds, placing $88.2 \%$ of beads below the critical depth of $2.6 \mathrm{~cm}$.
\end{abstract} characterized after excavation with a custom-built sampling device. The proportion of pseudosclerotia placed below the critical depth of $2.6 \mathrm{~cm}$
Additional keywords: tillage, Vaccinium spp.
Mummy berry is one of the most prevalent and destructive diseases of blueberry (Vaccinium spp.) in North America $(1,2,8)$. The disease is caused by the discomycete Monilinia vacciniicorymbosi, which oversummers and overwinters in infected, mummified fruit (pseudosclerotia) on the orchard floor. Pseudosclerotia germinate carpogenically in late winter to early spring and produce apothecia, the sole source of primary inoculum. Ascospores discharged from apothecia infect young, expanding vegetative tissues in the spring, causing a leaf and shoot blight. Conidia produced on the blighted leaves and shoots subsequently infect open flowers via the gynoecial pathway followed by stromatization of mycelia in the developing fruit and associated fruit mummification $(14,19)$. Pseudosclerotia drop to the orchard floor prior to or during harvest, completing the disease cycle $(1,9,21)$.

In commercial blueberry production in Georgia, mummy berry disease is managed primarily by repeated fungicide sprays from vegetative bud break to the end of bloom $(16,18)$. Substantial yield losses can still occur, however, indicating that this strategy does not always provide optimal disease control. Furthermore, there is an expanding market from consumers who prefer pesticide-free fruit, especially in pick-your-own plantings. Alternative disease management approaches are therefore needed to supple-

Corresponding author: H. Scherm; E-mail address: scherm@uga.edu

Publication no. P-2002-0528-02R

(C) 2002 The American Phytopathological Society ment current disease controls. From an epidemiological viewpoint, management tactics targeting pseudosclerotia on the ground could be very effective given that pseudosclerotia are the only source of primary inoculum of $M$. vaccinii-corymbosi $(1,9,21)$.

In a recent survey, we documented that approximately one-third of Georgia blueberry producers regularly use mechanical cultivation on their farms (16). Although cultivation is used primarily for weed control, it may offer additional benefits by burying or destroying pseudosclerotia of $M$. vaccinii-corymbosi $(8,13)$, but this has not been evaluated systematically. Pseudosclerotia buried experimentally below a certain depth failed to produce apothecia (13), indicating that depth of burial is critical to the success of cultivation as a means of mummy berry management. However, no information is available regarding the vertical distribution profiles of pseudosclerotia that result from different cultivation methods. For example, blueberry producers in Georgia employ a wide range of cultivation methods that differ in the type, number, and succession of implements used (H. Scherm, H. K. Ngugi, and D. S. NeSmith, unpublished data). These factors determine cultivation depth (which would affect apothecial emergence from pseudosclerotia) and proximity of operation of tillage implements relative to the blueberry plants (which would affect the proportion of pseudosclerotia on the ground that can be reached effectively).

The objectives of this study were to (i) assess the effect of depth of burial on apothecial emergence from pseudosclerotia of $M$. vaccinii-corymbosi; (ii) characterize the vertical distribution of pseudosclerotia in the topsoil following cultivation with different 
implements used commonly for cultivation in blueberry production; and (iii) determine accessibility of pseudosclerotia on the orchard floor by these implements. These objectives were studied in separate experiments, and results were combined mathematically to estimate potential reductions in the risk associated with primary inoculum for different cultivation methods.

\section{MATERIALS AND METHODS}

Apothecial emergence in relation to burial depth. Mature pseudosclerotia of $M$. vaccinii-corymbosi were collected in late fall from cv. Climax in two rabbiteye blueberry ( $V$. ashei) plantings. Pseudosclerotia were buried at depths of $0,1.5,3,6$, or $10 \mathrm{~cm}$ in 15.2-cm-diameter clay pots containing soil from a commercial blueberry planting in southern Georgia (Pelham Loamy Sand; $96 \%$ sand and $4 \%$ silt); the soil was sifted with a $2.4-\mathrm{mm}$ screen before use. Each pot contained 50 pseudosclerotia, and there were at least four replicates of each burial depth arranged in a randomized complete block design. Pots were placed either outdoors or indoors, with each environment repeated once. In the outdoor experiments, pots were partially buried in a sand bed on the campus of the University of Georgia, Athens, and the experimental area was irrigated with microsprinklers for $15 \mathrm{~min}$ each day. In the indoor experiments, pots were incubated in a growth chamber with average day and night temperatures of 21 and $16^{\circ} \mathrm{C}$, relative humidity $>95 \%$ maintained with humidifiers, and $14 \mathrm{~h}$ light (photon flux density 90 to $120 \mu \mathrm{mol} \mathrm{m} \mathrm{m}^{-2} \mathrm{~s}^{-1}$ ). Because the pseudosclerotia used in one of the indoor experiments had not received sufficient chilling for carpogenic germination at the time of their collection in the field, pots with these pseudosclerotia were incubated at $6^{\circ} \mathrm{C}$ in the dark for 4 weeks before being placed in the growth chamber (17). Soils were watered daily by adding tap water to the saucers underneath each pot.

In each experiment, the number of apothecia emerging from pseudosclerotia was counted three times a week from late winter through spring. The number of apothecia for each burial depth was averaged across replicates, expressed as a proportion of the maximum number of apothecia observed in each experiment, and plotted against depth of burial. The relationship between apothecial emergence and depth, $d$, denoted by $g(d)$ henceforth, was described by regression analysis.

Vertical distribution of pseudosclerotia and plastic beads following cultivation. Experiments were carried out at the University of Georgia Blueberry Research Farm, Alapaha, to (i) compare vertical distribution profiles of pseudosclerotia among different tillage implements; and (ii) determine whether vertical distribution profiles of pseudosclerotia and plastic beads would be similar to allow the use of beads as surrogates for pseudosclerotia in subsequent experiments in commercial plantings to avoid introducing inoculum of $M$. vaccinii-corymbosi.

The soil at this site is a Leefield Loamy Sand (98\% sand and $2 \%$ silt) with an organic matter content of $1.6 \%$ and had a soil moisture content of $14.4 \%$ at the time when the experiments were carried out. Pseudosclerotia (mean diameter $7.5 \mathrm{~mm}$ ) were collected from a rabbiteye blueberry planting and spray-painted bright red before use to aid in their detection and recovery following cultivation. A mixture of 100 pseudosclerotia and 100 faceted plastic beads (8.0-mm diameter; The Beadery, Hope Valley, RI) was distributed evenly on the surface of experimental plots $(25 \times$ $25 \mathrm{~cm}^{2}$ ) before cultivation with either an in-row rotary cultivator (Hester Plow Co., Lake City, FL) at a speed of $3.7 \mathrm{~km} \mathrm{~h}^{-1}$, a disc harrow (Bush Hog, Selma, AL) at $3.9 \mathrm{~km} \mathrm{~h}^{-1}$, or a rotary culti-

\begin{abstract}
Accessibility of pseudosclerotia by implements
\end{abstract}

Effect of cultivation
on apothecial
emergence

Proportion of pseudosclerotia able to form apothecia

\author{
Relative risk of \\ apothecial \\ emergence
}

Fig. 1. Outline of the procedure for calculating relative risk of apothecial emergence from pseudosclerotia of Monilinia vaccinii-corymbosi following cultivation with different implements. The proportion of pseudosclerotia on the ground inaccessible by a given implement $i, \lambda_{i}$, was considered to produce apothecia at the same level as pseudosclerotia placed on the soil surface in the burial experiments described in the text. The accessible proportion of pseudosclerotia, $1-\lambda_{i}$, was deemed to follow the vertical distribution profile, $v_{i}(d)$, as obtained from the cultivation experiments described in the text. Apothecial emergence from these pseudosclerotia was calculated by multiplying $v_{i}(d)$ with $g(d)$, the function describing apothecial emergence in relation to depth as obtained from the burial experiments. The resulting relative risk value is a number scaled between 0 (lowest possible risk) and 1 (greatest risk). 
vator (Maletti, Modena, Italy) at $3.7 \mathrm{~km} \mathrm{~h}^{-1}$. Depth settings were $5.1,10.1$, and $15.2 \mathrm{~cm}$ for the in-row rotary cultivator, the disc harrow, and the rotary cultivator, respectively. Each implement was used in a single pass starting $\approx 15 \mathrm{~m}$ ahead of each plot to allow for proper speed and depth adjustment. Plots were arranged in a randomized complete block design with three treatments (tillage implements) and four replicates. The experiment was repeated once with beads only.

Following cultivation, the soil was allowed to settle for at least 2 weeks, at which time pseudosclerotia and beads were excavated with a custom-built sampling device to determine their vertical distribution. This device consisted of an open metal frame $(40 \times$ $40 \mathrm{~cm}^{2}$ area and $15 \mathrm{~cm}$ high) with a removable panel on one side that served as a guide rail for removable metal trays of different depths, thereby allowing the removal of soil layers at precise depths of 2, 4, 7, and $10 \mathrm{~cm}$. The frame was hammered into the soil so that its top was level with the soil surface. A ditch was dug to expose the side of the frame with the removable panel. The panel was detached and, starting with the shallowest depth, the trays were inserted sequentially into the frame, and the soil collected in each tray was sifted to recover beads and pseudosclerotia. The number of pseudosclerotia or beads recovered from the soil surface and from each layer was determined, expressed as a proportion of the total number recovered, and the resulting frequency distribution was modeled using the Gamma or Gaussian probability distribution (10). The vertical distribution function for implement $i$ is denoted by $v_{i}(d)$ henceforth. The relationship between the numbers of pseudosclerotia and beads recovered from each soil layer across the three implements was determined by linear regression analysis.

Horizontal distribution of pseudosclerotia on the orchard floor and accessibility by cultivation. Tillage implements differ in how close to the blueberry plants they can be operated, thereby affecting the proportion of pseudosclerotia on the ground that can be reached effectively. To adjust for this effect when assessing the efficacy of implements, the distribution of pseudosclerotia with distance from the plant rows was determined in two rabbiteye blueberry plantings with a high incidence of mummy berry disease after fruit harvest in July. In each planting, pseudosclerotia located 0 to 10,10 to 20,20 to 30,30 to 40,40 to 60,60 to 80,80 to 120,120 to 160 , and 160 to $200 \mathrm{~cm}$ from the plant rows were counted in four replicate transects. Each transect encompassed the entire area under the canopy of a single plant on one side of the row and extended to the center of the row middle. Count data for each sampling distance were expressed as a proportion of the transect total, adjusted for area sampled, and averaged across the four replicates. Means and standard errors were plotted against the midpoint of the sampling distance, and a three-parameter Gaussian distribution was used to describe the resulting frequency distributions. Goodness-of-fit was judged based on plots of fitted values against observed values and the magnitude of residual deviance (12). A deviance ratio was used to test for between-site performance of the model, and data were pooled and the model fit to combined data in the absence of significant differences between sites.

Estimates of how close to the plant rows the in-row rotary cultivator, the disc harrow, and the rotary cultivator can operate were obtained by running each implement in a mature blueberry plant-

\section{Proportion of maximum number of apothecia emerging}

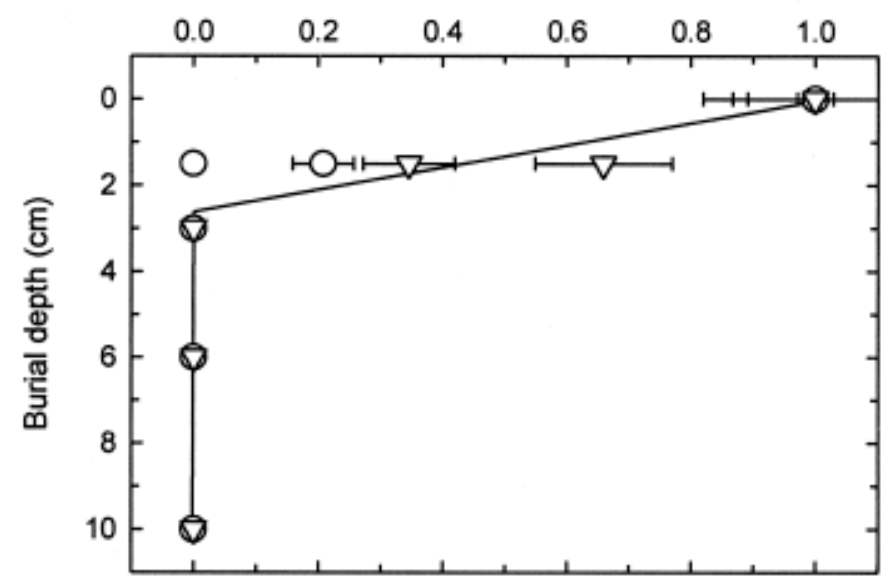

Fig. 2. Apothecial emergence from 50 pseudosclerotia of Monilinia vacciniicorymbosi buried at different depths expressed as a proportion of the maximum number of apothecia observed in each of four separate experiments; the maximum number of apothecia per experiment ranged from 5 to 34. Experiments were carried out in a growth chamber $(\nabla)$ or in the field $(O)$, each repeated once. Values are means and standard errors of four and five replicates for growth chamber and field experiments, respectively. Some data points overlap.

TABLE 1. Description of soil conditions on commercial farms where the effect of mechanical cultivation on vertical distribution of plastic beads, used as surrogates for pseudosclerotia of Monilinia vaccinii-corymbosi, was investigated

\begin{tabular}{lllcccr}
\hline & & & \multicolumn{3}{c}{ Texture $(\%)$} & \\
\cline { 3 - 5 } Site & County & Soil type & Sand & Silt & Clay & Organic matter content $(\%)$ \\
\hline Farm I & Bacon & Pelham Loamy Sand & 96 & 4 & 0 & 2.9 \\
Farm II & Appling & Pelham Loamy Sand & 92 & 6 & 2 & 1.8 \\
Farm III & Appling & Pelham Loamy Sand & 94 & 4 & 2 & 6 \\
Farm IV & Appling & Surrency Loamy Sand & 92 & 4 & 4 & 6.2 \\
\hline
\end{tabular}

TABLE 2. Description of tillage implements used on commercial farms where the effect of mechanical cultivation on vertical distribution of plastic beads, used as surrogates for pseudosclerotia of Monilinia vaccinii-corymbosi, was investigated

\begin{tabular}{|c|c|c|c|c|c|}
\hline Site & Implement(s) used & Number of passes & Operating speed $\left(\mathrm{km} \mathrm{h}^{-1}\right)$ & Depth setting $(\mathrm{cm})$ & Soil moisture content $(\%)^{\mathrm{a}}$ \\
\hline Farm I & In-row tined tiller & 3 & $3.5,6.0,6.0$ & 15.2 & 16.4 \\
\hline \multirow{2}{*}{ Farm II } & Bed shaper & 1 & 9.6 & 15.2 & 9.7 \\
\hline & Rotary cultivator & 1 & 2.4 & 3.9 & $\ldots$ \\
\hline Farm III & Rotary cultivator & 1 & 2.5 & $3.9-5.0$ & 8.8 \\
\hline \multirow[t]{3}{*}{ Farm IV } & In-row tined tiller & 1 & 2.4 & 7.6 & 14.1 \\
\hline & Flail mower & 1 & 5.6 & $-^{\mathrm{b}}$ & $\ldots$ \\
\hline & Rotary cultivator & 1 & 5.6 & 5.1 & $\ldots$ \\
\hline
\end{tabular}

\footnotetext{
${ }^{a}$ Determined gravimetrically.
}

${ }^{b}$ Operated on the soil surface. 
ing and measuring the distance between the line of tillage and the plant crowns for 10 randomly selected plants. The proportion of pseudosclerotia located between the crown and the line of tillage for each implement was calculated using the cumulative density distribution of the Gaussian function derived previously. For implement $i$, this inaccessible proportion of pseudosclerotia is denoted by $\lambda_{i}$ henceforth.

Relative risk of apothecial emergence following cultivation. In comparing relative risk of apothecial emergence following cultivation with different implements, the proportion of pseudosclerotia on the ground inaccessible by a given implement, $\lambda_{i}$, was considered to produce apothecia at the same level as pseudosclerotia placed on the soil surface in the burial experiments. The accessible proportion of pseudosclerotia, $1-\lambda_{i}$, was deemed to follow the vertical distribution profile, $v_{i}(d)$, as obtained in the cultivation experiments. Apothecial emergence from these pseudosclerotia was calculated by multiplying $v_{i}(d)$ with $g(d)$, the function describing apothecial emergence in relation to depth as obtained in the burial experiments. Figure 1 illustrates the procedure to calculate relative risk of apothecial emergence for different implements. The resulting relative risk value is a number scaled between 0 (lowest possible risk) and 1 (greatest risk).
Appraisal of commercial cultivation methods. To compare the efficacy of cultivation methods currently used commercially, the vertical distribution profiles of plastic beads following cultivation were determined on four blueberry farms in southern Georgia (Table 1). On each farm, 100 beads were distributed evenly on the surface of four replicate plots $\left(25 \times 25 \mathrm{~cm}^{2}\right)$ and located $20 \mathrm{~cm}$ from the plant rows. Plots were then cultivated according to the standard practices for each farm, and the soil was allowed to settle for at least 2 weeks before excavation of beads. Details of equipment operation and soil conditions at the time of cultivation are described in Table 2. Recovery of beads and data analysis were as described for experiments at the research farm.

\section{RESULTS}

Apothecial emergence in relation to burial depth. In all experiments, the greatest number of apothecia emerged from pseudosclerotia placed on the soil surface followed by those buried at $1.5 \mathrm{~cm}$ (Fig. 2). Emergence decreased by more than half as burial depth increased from 0 to $1.5 \mathrm{~cm}$. No apothecia emerged from pseudosclerotia buried at $\geq 3 \mathrm{~cm}$ below the surface. For depths up to $3 \mathrm{~cm}$, the proportion of apothecia emerging from

\section{Proportion recovered}
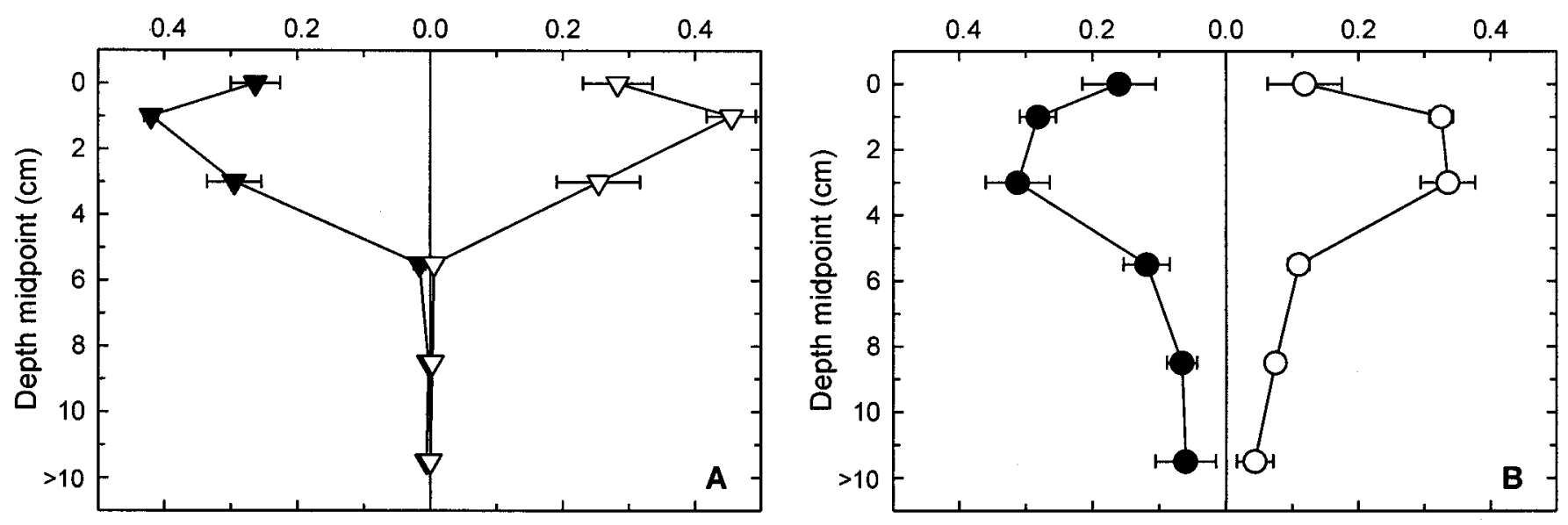

Proportion recovered
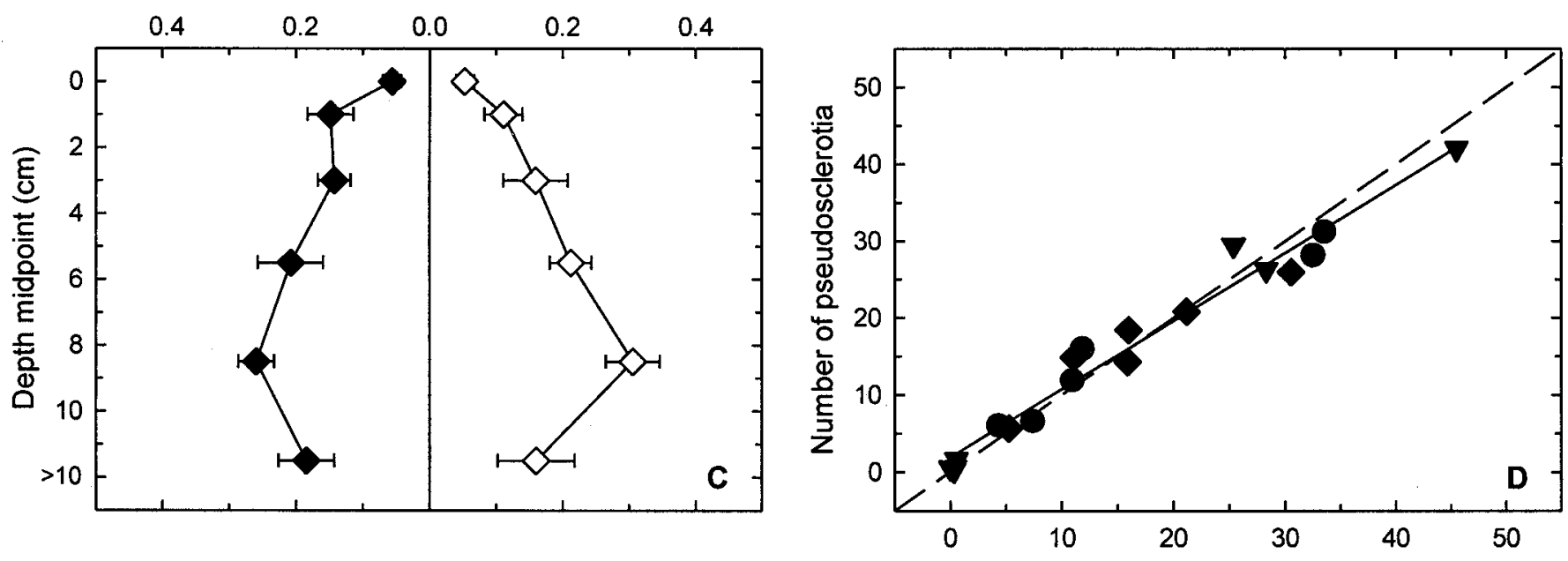

Number of beads

Fig. 3. Vertical distribution of pseudosclerotia of Monilinia vaccinii-corymbosi (solid symbols) and of plastic beads (used as surrogates for pseudosclerotia; open symbols) following cultivation with $\mathbf{A}$, an in-row rotary tiller, $\mathbf{B}$, a disc harrow, and $\mathbf{C}$, a rotary cultivator. Values are means and standard errors of four replicate plots with 100 pseudosclerotia and 100 beads per plot. D, Also shown is the relationship between the numbers of pseudosclerotia and beads recovered from different depths following cultivation with these implements. The regression slope $(b=0.894)$ of the fitted relationship (solid line) is not significantly different $(P=0.632)$ from unity (dashed line). Values are means of four replicate plots. 
each depth was described by the relationship $g(d)=0.934-$ $0.353 d(r=0.926, P<0.001, n=12)$ for the combined data from all four experiments. Based on the zero-intercept of this equation, the critical depth for inhibiting apothecial emergence was determined as $2.6 \pm 0.41(\mathrm{SE}) \mathrm{cm}$.

Vertical distribution of pseudosclerotia and plastic beads following cultivation. Recovery of pseudosclerotia or beads ranged from 74 to $100 \%$ and was not different among the three implements tested (data not shown). For both pseudosclerotia and beads, vertical distribution profiles differed considerably among the implements (Fig. 3A to C). For example, the in-row rotary cultivator placed $20.9 \%$ of pseudosclerotia below $2.6 \mathrm{~cm}$, the critical depth for apothecial emergence, compared with 52.6 and $78.6 \%$ for the disc harrow and the rotary cultivator, respectively. When the experiment was repeated with beads, the proportion placed below $2.6 \mathrm{~cm}$ was $18.8 \%$ for the in-row rotary tiller, $62.8 \%$ for the disc harrow, and $79.9 \%$ for the rotary cultivator. Vertical distribution profiles for the in-row rotary cultivator and the disc harrow were best described by the Gamma distribution with a $X^{2}$ probability for the residual deviance of $>0.05$. By contrast, a three-parameter Gaussian distribution $(P=0.327$ for residual deviance) best described the vertical distribution profile for the rotary cultivator.

For each of the three tillage implements, there was a close relationship between the numbers of pseudosclerotia and beads recovered from each depth (Fig. 3D). Across the three implements, the two variables were strongly correlated $(r=0.986, P<0.0001$, $n=18)$, and the slope of 0.894 was not significantly different from unity $(P=0.632)$.

Horizontal distribution of pseudosclerotia on the orchard floor and accessibility by cultivation. Most pseudosclerotia on the ground at the two sites were located within $100 \mathrm{~cm}$ from the crown of the plants, with the greatest numbers between 30 and $40 \mathrm{~cm}$ (Fig. 4). There was no significant difference $(P=0.386$ for deviance ratio) between sites in the distribution of pseudosclerotia, allowing data to be combined. The three-parameter Gaussian distribution provided a good fit for the combined data ( $P=0.398$ for residual deviance).

The in-row rotary cultivator could operate to a distance of $6 \mathrm{~cm}$ from the crowns of the plants, indicating good access to pseudosclerotia under the blueberry canopy. By contrast, the lines of tillage were 30 and $29 \mathrm{~cm}$ from the crown for the disc harrow and

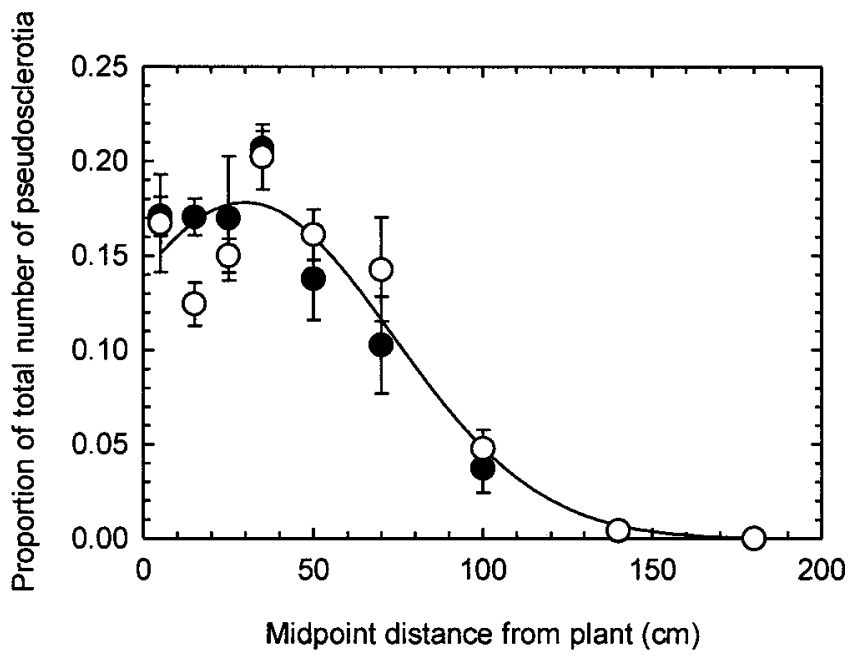

Fig. 4. Horizontal distribution of pseudosclerotia of Monilinia vacciniicorymbosi on the orchard floor with increasing distance perpendicular to the plant rows in two infested rabbiteye blueberry plantings after harvest. Open and closed symbols represent the two sites, and values are means and standard errors of four sampling transects per site. The line is a three-parameter Gaussian distribution fitted to combined data from both sites. the rotary cultivator, respectively. Using these values in the Gaussian cumulative distribution, the proportion of inaccessible pseudosclerotia, $\lambda_{i}$, was calculated as $12.8,41.3$, and $39.2 \%$ for the in-row rotary cultivator, the disc harrow, and the rotary cultivator, respectively.

Relative risk of apothecial emergence following cultivation. When results from the experiments on apothecial emergence and vertical and horizontal distribution of pseudosclerotia were combined as outlined schematically in Figure 1, resulting estimates of relative risk of apothecial emergence were lowest for the rotary cultivator (0.46) followed by the disc harrow (0.59) and the in-row rotary cultivator (0.60). These values suggest that cultivation with a single implement could reduce risk of apothecial emergence by about half compared with a scenario in which no cultivation is applied and all pseudosclerotia remain on the soil surface.

Appraisal of commercial cultivation methods. Considerable differences were observed in cultivation methods used by commercial blueberry producers (Table 2 ). These ranged from a single pass with a single implement (farm III) to multiple passes with the same implement (farm I) or consecutive passes with different implements (farms II and IV). Cultivation on three of the four farms resulted in shallow burial of beads, placing $<50 \%$ below $2.6 \mathrm{~cm}$ (Fig. 5). Only extensive reshaping of the beds, such as practiced on farm II (Fig. 5B), resulted in $88.2 \%$ of beads placed deeper than $2.6 \mathrm{~cm}$. A rotary cultivator used by one of the commercial producers placed only $27.4 \%$ of beads below $2.6 \mathrm{~cm}$ (Fig. $5 \mathrm{~A})$. This proportion was considerably lower than that of the rotary cultivator used on the research farm (82.0\%) (Fig. 3C),

\section{Proportion recovered}

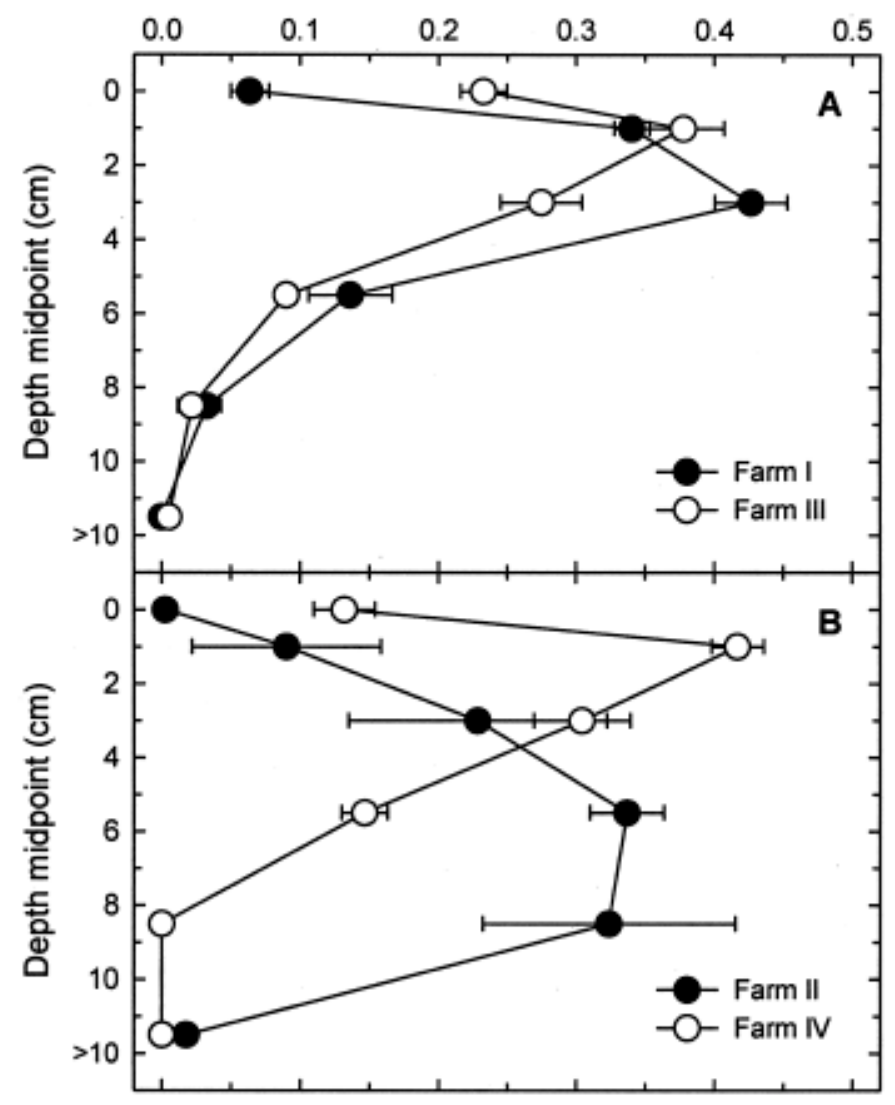

Fig. 5. Vertical distribution of plastic beads (used as surrogates for pseudosclerotia of Monilinia vaccinii-corymbosi) following cultivation methods used by four commercial blueberry producers. Methods employed: A, one tillage implement or $\mathbf{B}$, a sequence of multiple implements. Table 2 describes the cultivation methods for each farm. Values are means and standard errors of four replicate plots with 100 beads per plot. 
possibly due to differences in tractor speed or depth adjustment between the two sites.

\section{DISCUSSION}

To the best of our knowledge, this is the first study in which the relative efficacy of cultivation in reducing emergence of apothecia, which provide the primary inoculum for mummy berry disease, was evaluated systematically based on data from separate experiments on (i) apothecial emergence in relation to depth; (ii) vertical distribution of pseudosclerotia following use of different tillage implements; and (iii) accessibility of pseudosclerotia near the plants by these implements. Mathematical combination of the results from these experiments allowed a relative risk index for apothecial emergence, a number scaled between 0 (lowest possible risk) and 1 (greatest risk), to be calculated. This number is not an absolute measure of the amount of primary inoculum or the risk of primary infection following cultivation because it does not consider numerous other pathogen, host, and environmental factors that influence apothecial emergence and primary infection $(6$, $11,13,17)$. Nevertheless, the index is useful for the direct comparison of the efficacy of different cultivation methods.

It has been reported previously that pseudosclerotia of $M$. vaccinii-corymbosi formed on highbush blueberry (V. corymbosum) and buried at least $2.5 \mathrm{~cm}$ below the surface failed to produce apothecia (13). The use of mechanical cultivation as a means of control for mummy berry disease has therefore been recommended for this crop $(8,14)$. Pseudosclerotia formed on rabbiteye blueberry differ from those on highbush blueberry in development and morphology, including size and maturity level at the time of fruit drop $(6,15)$, and it was therefore necessary to revisit the effect of burial depth on apothecial emergence with pseudosclerotia from the former species. In the present study, the critical depth to prevent apothecial emergence for pseudosclerotia formed on rabbiteye blueberry was $2.6 \mathrm{~cm}$, a value very similar to the depth of $2.5 \mathrm{~cm}$ reported by Milholland (13) and within the 2- to 4-cm range reported for sclerotia of the closely related Sclerotinia sclerotiorum (20). This indicates that $2.6 \mathrm{~cm}$ is a reasonable target for burial when evaluating efficacy of implements and that the critical depth for inhibiting apothecial emergence may not be affected by the blueberry species on which pseudosclerotia are formed.

Apart from the critical depth of burial, the efficacy of cultivation as a means for disease control is largely influenced by the vertical distribution of inoculum in the topsoil following cultivation. Considerable differences in vertical distribution profiles of pseudosclerotia or beads were observed among cultivation methods involving single implement or a succession of multiple implements. Results showed that for most methods a large proportion of pseudosclerotia was buried at a depth too shallow to prevent apothecial emergence. For all but three methods (disc harrow and rotary cultivator on the research farm and three passes of different implements on farm II), more than $50 \%$ of pseudosclerotia were either left on the soil surface or buried between 0 and $2.6 \mathrm{~cm}$. This suggests that cultivation alone is unlikely to eliminate primary inoculum of $M$. vaccinii-corymbosi. Improved control may result from a combination of cultivation with other practices aimed at inhibiting germination of pseudosclerotia or development of apothecia, such as use of soil-applied desiccants or certain herbicides $(5,7)$.

The efficacy of cultivation is also affected by the horizontal distribution of pseudosclerotia on the orchard floor and their proximity to the crowns of the plants. This is important because implement design and operation limitations (e.g., concerns about damage to plant roots) determine how close to the plants the implements can be operated and consequently the proportion of pseudosclerotia accessible by cultivation. The distribution of pseudosclerotia with distance from the plants followed a Gaussian distribution with a peak between 30 and $40 \mathrm{~cm}$ away from the plant. To be effective, tillage implements need to operate well within this distance from the plant. Only one of the implements evaluated on the research farm, the in-row rotary cultivator, could be operated very close to the plant rows, and calculations indicated that $87.2 \%$ of pseudosclerotia were accessible by this implement. However, this implement also resulted in the shallowest burial of pseudosclerotia, indicating a trade-off between accessibility and depth of operation.

The ideal cultivation method is one that can access a large proportion of pseudosclerotia on the orchard floor and is capable of burying them below $2.6 \mathrm{~cm}$. Because of the trade-off between reach and depth of operation, no single implement is likely to meet these two requirements at the same time. Efficiency of mechanical cultivation may be improved by combining implements that have good access to pseudosclerotia near the plant rows with those that result in deep burial. The feasibility of this approach is illustrated by results obtained on farm II where a combination of three implements resulted in burial of $88.2 \%$ of beads below the critical depth.

This study did not address the effect of timing of cultivation on viability of pseudosclerotia and risk of apothecial emergence in subsequent years. Most pseudosclerotia of $M$. vaccinii-corymbosi left on the soil surface or buried to a shallow depth would disintegrate before being able to germinate carpogenically $(6,21)$. Nevertheless, a small proportion of pseudosclerotia may remain viable for periods exceeding 1 year. Indeed, in the closely related fungi $M$. fructicola and Sclerotinia spp., some pseudosclerotia or sclerotia remained viable for more than 6 years $(2-4)$. Further research is therefore needed to determine (i) the effect of burial at different depths on survival and viability of pseudosclerotia of $M$. vaccinii-corymbosi and (ii) the likelihood of pseudosclerotia buried below $2.6 \mathrm{~cm}$ remaining viable and being unearthed to depths within which apothecial emergence is possible when cultivating in subsequent years.

\section{ACKNOWLEDGMENTS}

Funded in part by the USDA-CSREES Pest Management Alternatives Program, grant 98-34381-6866. We thank J. Nugent, E. Moncrief, R. Rivers, and J. Roberts for technical support in the field; J. Clark and R. Blackley for arranging experiments with commercial blueberry producers; and H. Carter, A. Miles, D. Morris, and S. Scarborough for access to their farms.

\section{LITERATURE CITED}

1. Batra, L. R. 1983. Monilinia vaccinii-corymbosi (Sclerotiniaceae): Its biology on blueberry and comparison with related species. Mycologia 75:131-152.

2. Batra, L. R. 1991. World Species of Monilinia (Fungi): Their Ecology, Biosystematics, and Control. Mycological Memoirs No. 16, J. Cramer, Berlin.

3. Ben-Yephet, Y., Genizi, A., and Siti, E. 1993. Sclerotial survival and apothecial production by Sclerotinia sclerotiorum following outbreaks of lettuce drop. Phytopathology 83:509-513.

4. Coley-Smith, J. R., Mitchell, C. M., and Sansford, C. E. 1990. Longterm survival of sclerotia of Sclerotium cepivorum and Stromatinia gladioli. Plant Pathol. 39:58-69.

5. Cox, K. D., and Scherm, H. 2001. Effect of desiccants and herbicides on germination of pseudosclerotia and development of apothecia of Monilinia vaccinii-corymbosi. Plant Dis. 85:436-441.

6. Cox, K. D., and Scherm, H. 2001. Oversummer survival of Monilinia vaccinii-corymbosi in relation to pseudosclerotial maturity and soil surface environment. Plant Dis. 85:723-730.

7. Fulton, R. H. 1958. Controlling mummy berry disease of blueberry by soil treatment. Q. Bull. Mich. Agric. Exp. Stn. 40:491-497.

8. Gough, R. E. 1994. The Highbush Blueberry and Its Management. Food Products Press, Binghamton, NY.

9. Honey, E. E. 1936. North American species of Monilinia. I. Occurrence, grouping and life-histories. Am. J. Bot. 23:100-106.

10. Johnson, N. L., Kotz, S., and Balakrishnan, N. 1994. Continuous Uni- 
variate Distributions. 2nd ed. John Wiley \& Sons, New York.

11. Lehman, J. S., and Oudemans, P. V. 1997. Phenology of the mummy berry fungus and its blueberry host: Implications for resistance breeding. Acta Hortic. 446:287-292.

12. McCullagh, P., and Nelder, J. A. 1983. Generalized Linear Models. Chapman and Hall, London.

13. Milholland, R. D. 1974. Factors affecting apothecium development of Monilinia vaccinii-corymbosi from mummified highbush blueberry fruit. Phytopathology 64:296-300.

14. Milholland, R. D. 1977. Sclerotium germination and histopathology of Monilinia vaccinii-corymbosi on highbush blueberry. Phytopathology 67:848-853.

15. Scherm, H., and Copes, W. E. 1999. Evaluation of methods to detect fruit infected by Monilinia vaccinii-corymbosi in mechanically harvested rabbiteye blueberry. Plant Dis. 83:799-805.

16. Scherm, H., NeSmith, D. S., Horton, D. L., and Krewer, G. 2001. A survey of horticultural and pest management practices of the Georgia blueberry industry. Small Fruits Rev. 1:17-28.

17. Scherm, H., Savelle, A. T., and Pusey, P. L. 2001. Interactions between chill-hours and degree-days affect carpogenic germination in Monilinia vaccinii-corymbosi. Phytopathology 91:77-83.

18. Scherm, H., and Stanaland, R. D. 2001. Evaluation of fungicide timing strategies for control of mummy berry disease of rabbiteye blueberry in Georgia. Small Fruits Rev. 1:69-81.

19. Shinners, T. C., and Olson, A. R. 1996. The gynoecial infection pathway of Monilinia vaccinii-corymbosi in lowbush blueberry (Vaccinium angustifolium). Can. J. Plant Sci. 76:493-497.

20. Singh, U. P., and Singh, R. B. 1983. The effect of soil texture, soil mixture, soil moisture and depth on carpogenic germination of Sclerotinia sclerotiorum. Z. Pflanzenkr. Pflanzenschutz 90:662-669.

21. Woronin, M. 1888. Über die Sclerotienkrankheit der Vaccinieen-Beeren. Mem. Acad. Imp. Sci. St.-Pétersbourg (VIIe Série) 36:1-49. 